\title{
Renal Osteodystrophy in Mullerian, Renal, Cervicothoracic Somite Abnormalities (MURCS Association): A Logical, However Hitherto Unknown Entity
}

\author{
Kishor Taori, Jawahar Rathod, Ramesh Parate, Amit Disawal, Suresh Dhakate, \\ Anand Hatgaonkar, Amrita Guha \\ Department of Radiodiagnosis, Government Medical College, Nagpur, India \\ Email: kishortaori@gmail.com, jawaharrathod_12@rediffmail.com, rameshparate@yahoo.com, \\ suresh_dhakate2007@rediffmail.com,amritaguha2006@yahoo.com
}

Received January 30, 2013; revised March 2, 2013; accepted March 10, 2013

Copyright (C) 2013 Kishor Taori et al. This is an open access article distributed under the Creative Commons Attribution License, which permits unrestricted use, distribution, and reproduction in any medium, provided the original work is properly cited.

\begin{abstract}
The MURCS association which stands for Mullerian, Renal, Cervicothoracic Somite Abnormalities is a rare developmental anomaly seen in females. The clinical course of this disorder is not clearly defined as of yet-which may range from asymptomatic to severe disability. Here we present the case of a young 22-year-old female who was incidentally detected to have a generalized increase in bone density with an absent uterus. Further workup revealed a case of MURCS association with renal osteodystrophy. This is an as of yet unreported complication/association and must be kept in mind in the treatment of these patients.
\end{abstract}

Keywords: MURCS Association; Renal Osteodystrophy; Absent Uterus

\section{Introduction}

MURCS association is a rare developmental disorder that affects females. The acronym MURCS stands for Mullerian, Renal, Cervicothoracic Somite Abnormalities and manifests itself as Mullerian duct aplasia or hypoplasia, unilateral renal agenesis and cervicothoracic somite dysplasia. Here we present a case of typical MURCS syndrome, who however presented to us for a different reason and which had not been suspected by the clinician and was diagnosed entirely by the radiologist. This patient had renal osteodystrophy which is an as of yet unreported association/complication in literature.

\section{Case Report}

A 22-year-old woman, married a year ago and who was short in stature on clinical examination came with complaints of back pain (Figure 1) for which she was advised a routine thoraco-lumbar spine radiograph. The radiographs revealed increased bone density with characteristic "Rugger jersey spine" (Figure 2). It was decided that this patient warranteed further work-up and we asked to meet the patient following which a complete skeletal survey was advised. The radiographs revealed generalized increase in bone density with a relative sparing of appendicular skeleton (Figure 3). Also, there was an incidental finding of fusion of C2-3 vertebral bodies (block vertebrae) (Figure 4).

Keeping a tentative diagnosis of renal osteodystrophy in mind, we decided to perform an ultrasound of the abdomen. It came as no surprise, when we noted that the

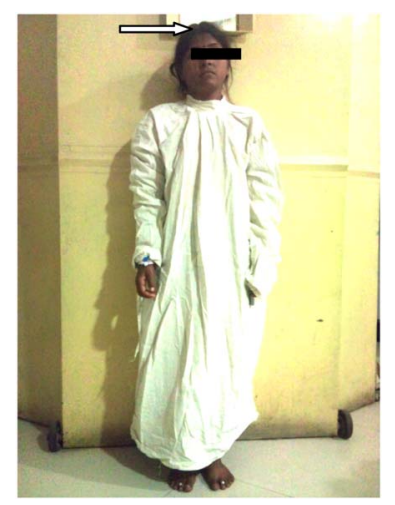

Figure 1. Short in stature $(138 \mathrm{~cm})$. However otherwise normal secondary sexual characteristics. 


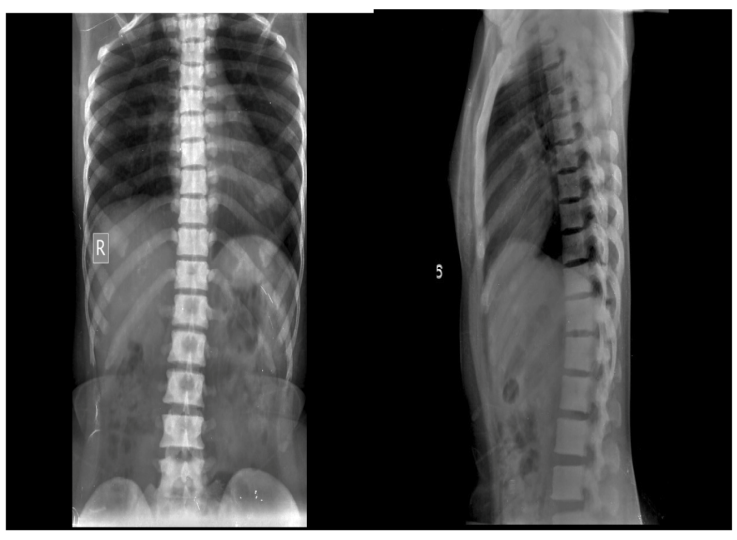

Figure 2. Thoracolumbar spine AP \& lateral view revealed increased bone density with characteristic "Rugger jersey spine".

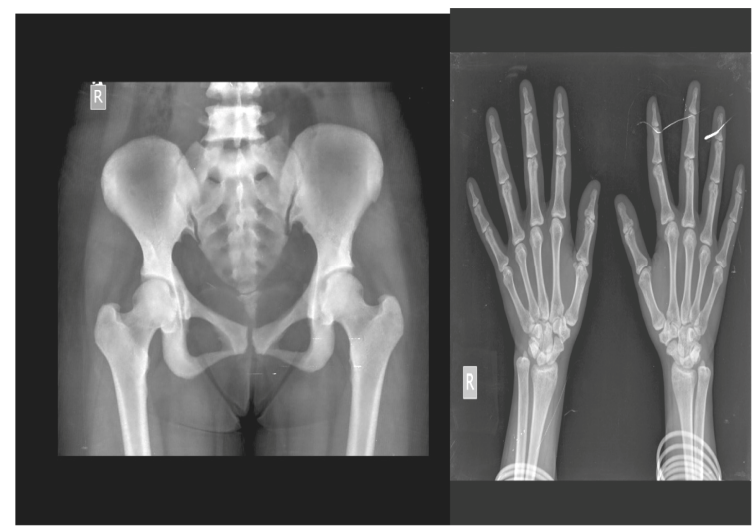

Figure 3. Radiograph pelvis with both hip joints revealed increase in bone density with relative sparing of the appendicular skeleton.

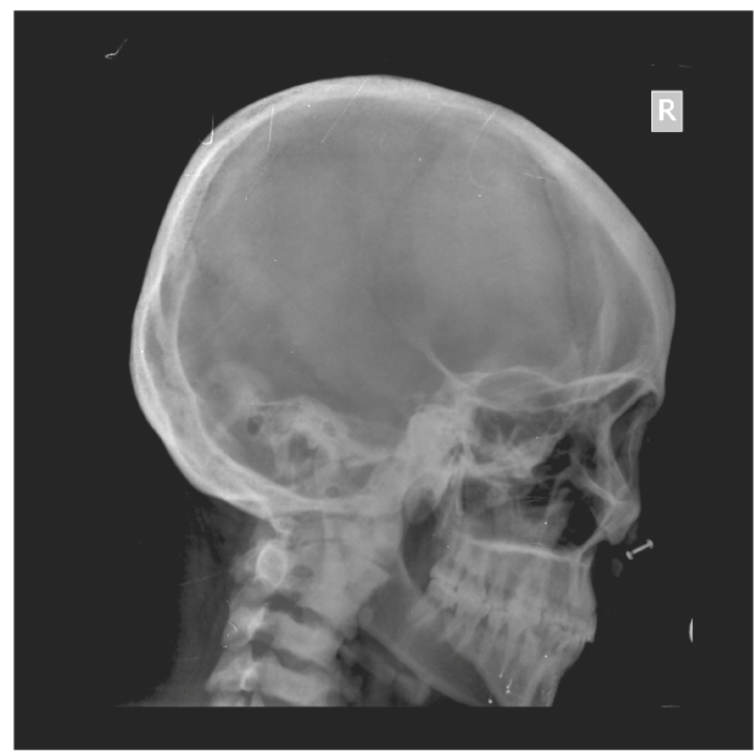

Figure 4. Radiograph skull lateral view revealed the incidental finding of congenital block vertebrae with $\mathrm{C} 2-\mathrm{C} 3$ fusion. patient had renal parenchymal disease grade II on the right side with multiple renal calculi (Figure 5) and an absent left kidney (Figure 6). Despite our best efforts, we could not visualize the uterus and MRI of the abdomen and pelvis was advised. This revealed an absent uterus with visualization of both ovaries s/o Mullerian Agenesis (Figures 7 and 8).

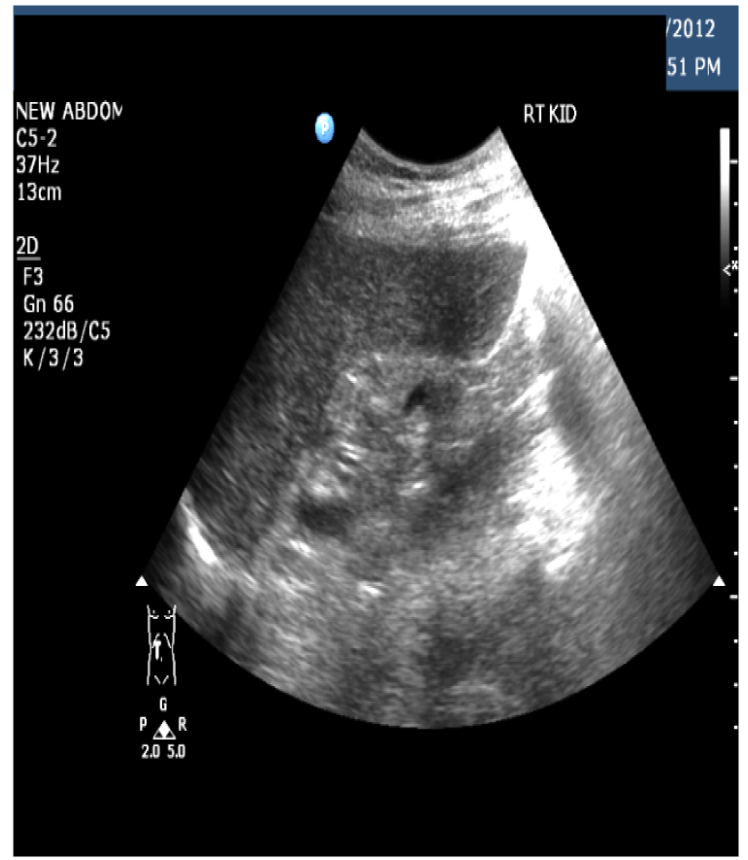

Figure 5. Ultrasound revealed increase in right renal echotexture s/o renal parenchymal disease.

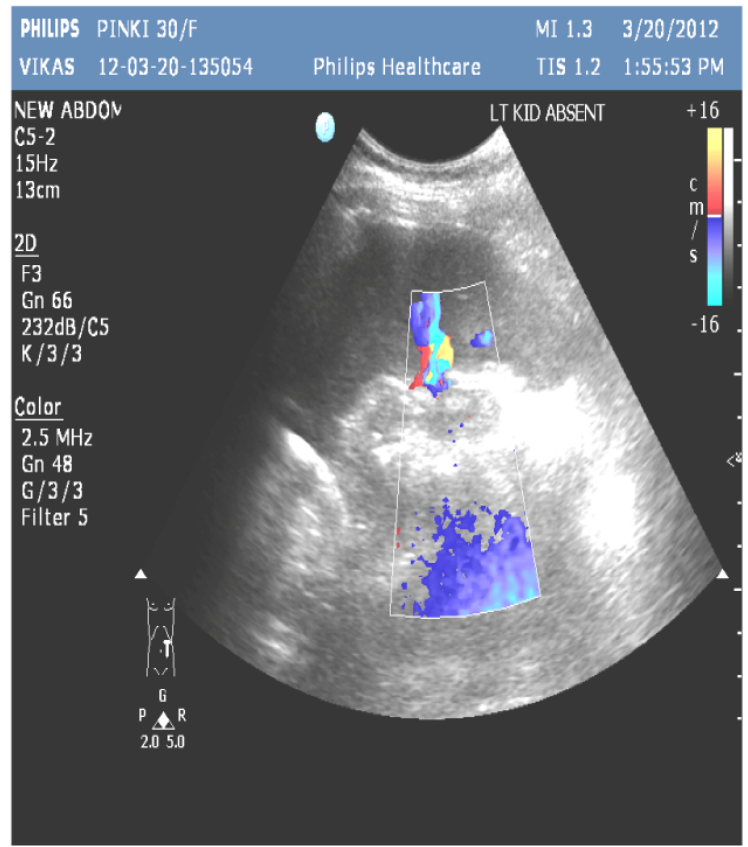

Figure 6. Ultrasound abdomen which revealed absent left kidney. 


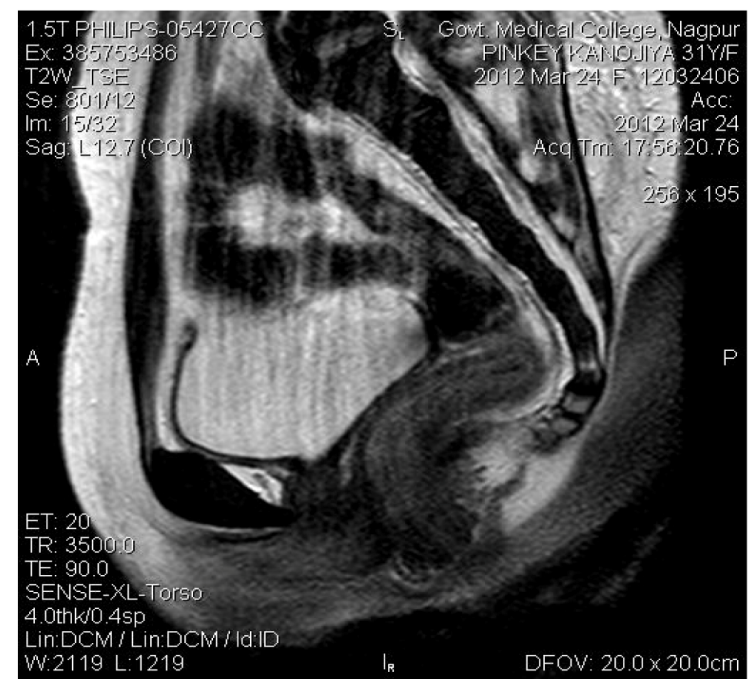

Figure 7. MRI pelvis saggital T2W image showing blind ending vaginal stump with absent uterus.

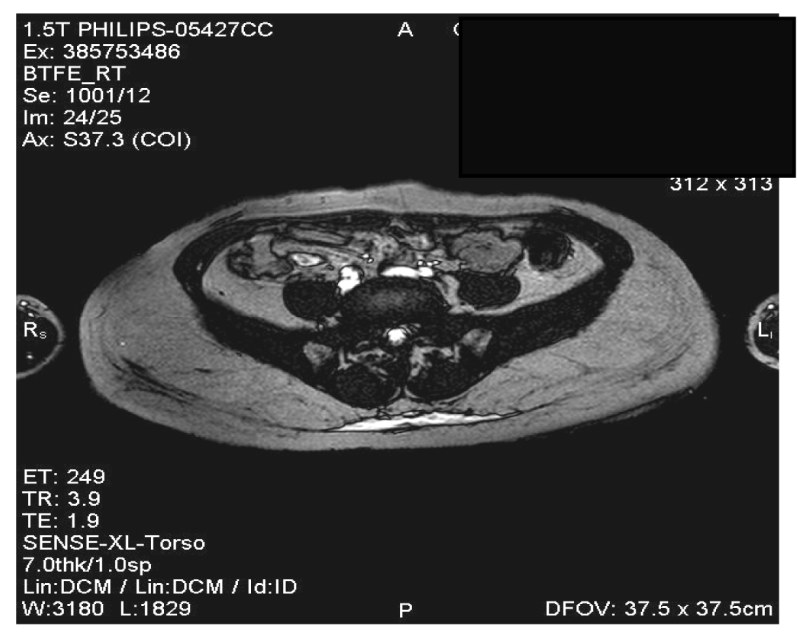

Figure 8. MR axial BTFE images showing both ovaries which appear normal. This explains the normal secondary sexual characteristics which were well developed in this patient.

There was no significant contributory medical history in either parent or sibling of the patient, or any exposure to any known teratogen in the antenatal period. In view of the above findings, considering the possibility of MURCS association, further haematological investigations were done. This lady who had short stature $(\mathrm{Ht}=$ $138 \mathrm{cms})$ also had severe anaemia $(\mathrm{Hb}=4.2 \mathrm{~g} \%)$ with decreased serum calcium, increased phosphate levels and serum alkaline phosphatase. Hence a final diagnosis of MURCS association with renal osteodystrophy was made. Patient is on regular follow up.

\section{Discussion}

The Rokitansky Kuster Hauser syndrome which is characterized by developmental failure of the Mullerian duct structures may occur with associated urinary tract abnormalities and skeletal abnormalities [1,2]. Duncan et al. [3] in 1979, in a review of 30 cases proposed the designation of the entity consisting of anomalies of all 3 systems as "MURCS Association". It appears to occur randomly (Sporadic) with a frequency of 1 in 50.000 females [4].

The four most common malformations specifically described in the association are: 1) Uterine hypoplasia or aplasia; 2) Renal agenesis or ectopy; 3) Vertebral anomalies; and 4) Adult stature less than $152 \mathrm{cms}$ [4]. Other minor abnormalities occasionally detected but absent in our case include upper limb defects, rib abnormalities, Sprengel's shoulder, deafness, external ear defects, facial asymmetry, cleft lip and palate, micrognathia and GI abnormalities [5].

The pathogenesis of this association is not clear. There were no obvious contributory clues regarding the etiology of this condition in our patient. Mendez et al. concluded that the MURCS association could be produced by a teratogenic event, which would affect the relations within these blastemas or most cases appear to be sporadic, though there are reports of families in which siblings displayed utero-vaginal abnormalities of the MURCS association [6].

Therefore, the MURCS association may be described as a polytopic field defect of multiple possible etiologies [7].

The prognosis of each case varies and is probably dependent on the extent and severity of renal abnormalities. The only autopsy report on a patient with MURCS association by Greene Robert et al. [1] revealed associated central nervous system, vascular and pulmonary abnormalities, probably indicating a multisystem involvement.

Differential diagnosis of MURCS association includes Goldenhar syndrome, VACTERL association, and Turner's syndrome. VACTERL association is rarely combined with genital anomalies and vertebral malformations are located more often in the caudal region. In Goldenhar syndrome urogenital abnormalities are rare.

In the original report of Duncan et al. uterine aplasia/hypoplasia, renal agenesis/ectopy, and anomalies of the cervical spine were only present in 16 out of 30 cases. Only 46 out of 65 previously published cases have had all three major manifestations. Therefore, the acronym MURCS should be restricted to women with all typical symptoms. Application to patients with only some of the typical manifestations is confusing and hinders the delineation from atypical cases of Klippel-Feil sequence, MRKH syndrome, or Goldenhar syndrome. MURCS association should be considered as a developmental field defect and only diagnosed if both aplasia/hypoplasia of the Mullerian duct, renal agenesis/ectopy, and anomalies of the cervicothoracic somites are present. 
Since these patients have a single kidney, they may be prone to calculi formation and renal parenchymal disease with age. However, the association with renal osteodystrophy has not been reported in literature. The exact pathogenesis of this needs to be studied so that such complications can be avoided and appropriate preventive measures initiated at an early level to decrease morbidity.

\section{REFERENCES}

[1] R. A. Greene, M. J. Bloch and D. S. Huff, "MURCS Association with Additional Congenital Anomalies,” Human Pathology, Vol. 17, No. 1, 1986, pp. 88-91. doi:10.1016/S0046-8177(86)80160-5

[2] W. N. P. Willemsen, "Renal, Skeletal, Ear and Facial Anomalies in Combination with the Mayer-Rokitansky Kuster (MRK) Syndrome,” European Journal of Obstetrics \& Gynecology and Reproductive Biology, Vol. 14, No. 2, 1982, pp. 121-130. doi:10.1016/0028-2243(82)90046-6

[3] P. A. Duncan, L. R. Shapiro, J. J. Stangel, R. M. Klein and J. C. Addonizio, "The MURCS Association: Millerian Duct Aplasia, Renal Aplasia, and Cervicothoracic
Somite Dysplasia,” Journal of Pediatrics, Vol. 95, No. 3, 1979, pp. 399-402. doi:10.1016/S0022-3476(79)80514-4

[4] C. Braun-Quentin, C. Billes, B. Bowingand D. Kotzot, "MURCS Association: Case Report and Review," Journal of Medical Genetics, Vol. 33, No. 7, 1996, pp. 618620. doi:10.1136/jmg.33.7.618

[5] R. A. Green, M. J. Bloch, D. S. Huff and R. V. Iozzo, "MURCS Association with Additional Congenital Anomalies,” Human Pathology, Vol. 17, No. 1, 1986, pp. 8891. doi:10.1016/S0046-8177(86)80160-5

[6] P. J. Mendez, A. Ulloa-Aguirre, F. J. Sanchez, O. Mutchinick and G. Perez-Palacios, "Endocrine Evaluation in a Patient with MURCS Association and Ovarian Agenesis," European Journal of Obstetrics \& Gynecology and Reproductive Biology, Vol. 22, No. 3, 1986, pp. 161-169. doi:10.1016/0028-2243(86)90062-6

[7] K. H. Orstavol, J. Steen-Johnson, A. Foerster, T. Fjeld, K. Skullerud and S. O. Lie, "VACTERL or MURCS Association in a Girl with Neurenteric Cyst and Identical Thoracic Malformations in the Father: A Case of Gonosomal Mosaicism?” American Journal of Medical Genetics, Vol. 43, No. 6, 1992, pp. 1035-1043. doi:10.1002/ajmg.1320430625 